\title{
Impact of metal(loid) on mineral transformation during sulfidation of Fe(III)-(oxyhydr)oxides
}

\author{
NARESH KUMAR', VINCENT NOËL ${ }^{2}$, KATHARINA \\ REINHOLD', STEPHAN KRAEMER' \\ University of Vienna, Vienna, Austria.
}

${ }_{2}^{2}$ LLAC National Accelerator Laboratory, Menlo Park, USA.

Fe(III)-(oxyhydr)oxide minerals are abundant in near and sub-surface environments and are important scavengers for a wide range of nutrients, metal(loids), and other aqueous and soil contaminants. In anaerobic environments, $\mathrm{Fe}(\mathrm{III})$-(oxyhydr)oxides undergo reduction by organic matter and/or microbial iron or sulfate reduction. Dissolved sulfide is a potent reductant and it is shown that the $\mathrm{S} / \mathrm{Fe}$ ratio controls the $\mathrm{Fe}(\mathrm{III})$-(oxyhydr)oxides sulfidation rate, the generation of dissolved and colloidal Fe and $\mathrm{S}$ species, as well as the newly formed $\mathrm{Fe}-\mathrm{S}$ minerals precipitation. In this context, reductive dissolution and precipitation of newly formed minerals can successively release or trap metal contaminants, thus, controlling their mobility. Paradoxically, the reverse impact of metal(loid) contaminants on the kinetics and thermodynamics of mineral dissolution and nucleation have received minimal attention. In this study, we evaluated the impact of metal(loid) on these redox transformations and, hence, on their own mobility.

We conducted batch experiments to unravel the role of surface sorbed contaminants on the secondary mineral precipitation during ferrihydrite sulfidation at varied $\mathrm{S} / \mathrm{Fe}$ ratios. We characterized mineral phases using synchrotron based x-ray absorption spectroscopy, $\mathrm{x}$-ray diffraction, and using wet chemical methods in presence and absence of surface sorbed contaminants over a period of time. Our results show that the presence of contaminants exert control over the kinetics and nature of mineral precipitation during sulfidation of ferrihydrite. Understanding this mineral transformation is key to pridict the contaminant mobility and remediation potential in envirnonmental systems. 